\title{
Verification of the reserve of Al-Hamada oil field V-NC6 area by application of well logs.
}

\author{
Tariq Basher*, Essa Tabar, Ali Omran
}

Department of Petroleum Engineering, College of Engineering, Sirte University, Libya DOI: https://doi.org/10.21467/proceedings.2.33

* Corresponding author email: tariq.alkaseh@gmil.com

\begin{abstract}
The motivation behind this paper is to enrich and deepen our knowledge in the field of logging and $\log$ interpretation. The ultimate target is to have in situ assaying of a particular zone. In petroleum application this means determining the amount of oil and/ or gas that is contained in the formation. The Geological structure of V- NC6 area in AL-HAMADA oil field has been studied and volumetrically estimated in seeks of the amount of hydrocarbons in the structure. To achieve this, a bunch of well logging data from different wells in V-NC6 area have been reviewed, analyzed and interpreted. Physical properties of the reservoir have been measured which include porosity and water saturation by interpretation of SP $\log$ and Induction - Electrical logs. In situ porosity has been determined by applying the Archie's equation on a real data from different resistivity tools. The average porosity of the multi pay zones structure was 14.23 $\%$ of the total volume of the reservoir 83336.3 acre $\mathrm{ft}$. The second basic parameter which has been determined for in situ assaying is the saturation of the V- NC6 structure with water and hydrocarbons and they were $30 \%$ and $70 \%$ respectively. The V- NC6 area in AL-HAMADA oil field volumetrically occupied around 5.44 Million Stock tank barrels of oil.

Keywords: well logging; log interpretation; resistivity log, SP $\log$, porosity; Water saturation.
\end{abstract}

\section{Introduction}

The volume of hydrocarbon reserves is a primary component of an energy company's value. Estimating that volume is a complicated, but essential and regulated, part of the resource industry's business. Geophysical methods continue to advance and are playing a more fundamental role in reservoir assessment (Hardage, 2009; PRMS-AD, 2011). To achieve this, physical properties of the reservoir have to be measured which include porosity and water saturation. Unfortunately, no one tool can give these results. Therefore, tool combinations that will measure porosity and hydrocarbons in place in the reservoir have been developed for various targets. Determining in situ properties (porosity and fluid saturation) can be done by the use of three porosity tool and resistivity tool as well. Those porosity tool that are used normally are the sonic, density and the Neutron porosity tools. A second basic parameters to be determined for in situ assaying is the saturation of the formation with hydrocarbons and

(C) 2018 Copyright held by the author(s). Published by AIJR Publisher in Proceedings of First Conference for Engineering Sciences and Technology (CEST-2018), September 25-27, 2018, vol. 1.

This is an open access article under Creative Commons Attribution-NonCommercial 4.0 International (CC BY-NC 4.0) license, which permits any non-commercial use, distribution, adaptation, and reproduction in any medium, as long as the original work is properly cited. ISBN: $978-81-936820-5-0$ 
Verification of the reserve of Al-Hamada oil field V-NC6 area by application of well logs

water. The V- NC6 area has been owned and running by the Arabian Gulf Oil Company, on November 1976 the reservoir engineers have been estimated the original hydrocarbons in place to be around $5 \mathrm{MM} \mathrm{STB}$, and this value was economically stratified for the operator to start production from this area. In this paper we tried to redo the same job and estimate the volume of hydrocarbons occupied originally in place.

\section{Materials and Methods}

Al Hamadah al hamra area is located on the southern flank of the Ghadamis basin between lat 29' $00^{\prime}$ to $29^{\prime} 40^{\prime} \mathrm{N}$ and long $12^{\prime} 35^{\prime}$ to $13^{\prime} 10^{\prime} \mathrm{E}$ occupying a strategic position midway between Al Qarqaf arch to the south and centre of the basin to the north. Over $1200 \mathrm{ft}$ of sediments are accumulated in the basin and range in age from Precambrian to Paleocene. While most of the lower two-thirds are clastics, the upper third is mostly marine carbonates and evaporates. Most of the lower Paleozoic units pinch out rapidly against AL Qaraqaf arch to the south in addition to their being cut off by several unconformities. These unconformities represent different erosodes during early and late Paleozoic and Mesozoic times.

Large ENE-WSW tending compressional faults and folds were associated with the early Alpine progeny which were later modified with smaller N-S and NW-SE normal faults.

Where; ENE - East North East and WSW - West South West

\subsection{Well Location and Prospective Horizons}

Based on correlation with the nearby wells, the following are the expected stratigraphic, table (1) shows tops of the interested zones in V8-NC8 well.

Table 1 shows tops of the interested zones in V8-NC8 well.

\begin{tabular}{|c|cc|}
\hline Lower Devonian & $\mathbf{- 2 9 5 0}$ & $\mathbf{F t}$ \\
\hline Do-Sandstone & -2950 & Ft. \\
\hline Do-Shale & -2969 & Ft. \\
\hline D1-Sandstone & -2917 & Ft. \\
\hline D1 -Shale & -3000 & Ft \\
\hline D2 -Sandstone & -3019 & Ft. \\
\hline D2 -Shale & -3065 & Ft. \\
\hline D3-Sandstone & -3083 & Ft. \\
\hline Total Depth & $\mathbf{- 3 2 5 0} \quad$ Ft. \\
\hline
\end{tabular}

\section{Theory and Calculation}

In this section we will show the calculation of each parameter we did use in our research and we have used real logs to interpret the data to come out with these results.

\subsection{Volumetric Method:}

The volumetric method requires the exactest possible data on :
a) The thickness of the reservoir rock.
b) Its extension. 
c) Its porosity and $\quad$ d) its saturation.

By a multiplication of these 4 factors we then get the original reserves in the field under reservoir conditions as in equation (1). The thickness of the pay horizon is usually obtained from downhole measurements (SP, resistance). As only the net thickness is measured

$$
N=\frac{7758 * A * h * \emptyset *\left(1-S_{w i)}\right.}{B_{\text {oi }}}
$$

Where; $\mathrm{N}=$ Oil in place STB, $\mathrm{A}=$ Productive area $\mathrm{Ft}^{2}, \mathrm{~h}=$ net thickness $\mathrm{Ft}, \emptyset=$ porosity $\%$

Swi $=$ connate water saturation $\%$, Boi $=$ Formation Volume Factor Rb/STB.

\subsection{Volumetric Reserve Calculation:}

\subsubsection{Thickness (h):}

The gross net pay thickness has been estimated from logs.

\subsubsection{Calculation of the bulk volume of the reservoir by using ISOPACH MAP:}

A net Isopach map is a map showing lines connecting points of equal net formation thickness. The bulk volume of the reservoir has been determined by using these maps. The Trapezoidal equation has been used to determine the volume of the production zones from planimeter reading.

\section{A) Trapezoidal Equation: \\ $\Delta V B_{n}=h / 2\left(A_{n-1}-A_{n}\right)$ \\ $B V=\left\{\Delta V B=h / 2\left(A_{0}+2 A_{1}+2 A_{2}\right)\right\}$}

This equation used when

$\frac{A_{n}}{A_{n-1}} \geq 0.5$

\subsubsection{Porosity $(\varnothing)$ :}

It is generally measured directly in the laboratory from cores or cutting and then plotted in a porosity profile these measurements are usually verified by various downhole measurements. In this paper we did use an Arche's equation to calculate the average porosity of multi strata reservoir.

$\emptyset_{\text {avg }}=\frac{\sum h * \emptyset}{\sum h}$

\subsubsection{Water saturation (SW):}

It is major factor the irreducible water saturation Swi is best established by capillary pressure measurements carried out on cores or cutting in addition to this the (archie) formula is also 
Verification of the reserve of Al-Hamada oil field V-NC6 area by application of well logs

useful in this respect an exact determination of the oil/water contact is usually difficult and requires experience.

\section{a. Calculation of water saturation (SW) from SP log}

The fluid saturation of a rock is the ratio of the volume of the fluid within the pores of the rock to the total pore volume. In this paper the water saturation has been calculated within two different methods; chart method and ARP'S equation method.

To estimate the water saturation of the formation must determine the Ro, Rt and Rw Where

Ro: oil resistivity , Rt: true resistivity, Rw: water resistivity \& F: formation resistivity factor ARP'S equation method:

Compute the constant $\mathrm{K}$

$\mathrm{K}=(60+.133 \mathrm{Tf})$

Where $\mathrm{K}$ : a termal convention constant.

Solve for Rweq

Rweq $=$ Rmfeq $/ 10^{\wedge}(-\mathrm{sp} / \mathrm{k})$

Convert Rweq to Rw

If Rweq $<0.12$ then use

$\mathrm{Rw}=\left(77 \mathrm{Rweq}_{\mathrm{w}}+5 / 146-(377 \mathrm{Rweq})\right.$.

If Rweq $>0.12$ then use

Where; $\mathrm{Rw}_{\mathrm{eq}}$ : Equivalent resistivity of the formation water, $\mathrm{R}_{\mathrm{mf}}$ : Resistivity of the mud filtrate and SSP : static SP the maximum deflection possible for a given Rmf/Rw.

$\mathrm{Rw}=-0.58+10^{\wedge}(0.69 \mathrm{Rw}$ eq -0.24$)$

$\mathrm{SW}=\sqrt{ }(\mathrm{Ro} / \mathrm{RT})$

$\mathrm{F}=\mathrm{Ro} / \mathrm{Rw}$

$\mathrm{Ro}=\mathrm{FRw}$

$\mathrm{Sw}=\sqrt{ }(\mathrm{FRw} / \mathrm{Rt}))$

\section{b. Formation factor $(F)$ :}

Archer experimentally determined that the formation factor could be determined from the porosity cementation $(\mathrm{m})$ and rock texture (a)

Thus $\left.\mathrm{F}=\mathrm{a} / \phi^{\wedge} \mathrm{m}\right)$

Though extensive use of the relationship the following values have been used with great success

$\mathrm{F}=\frac{R o}{R w}=\frac{\text { resistivity of rock saturated with } \mathrm{fluid}}{\text { resistivity of the saturating } \mathrm{fluid}}$

Where ; $\mathrm{R}_{\mathrm{m}}$ : Resistivity of the mud, $\mathrm{R}_{\mathrm{mf}}$ : Resistivity of the mud filtrate, Rmc - Resistivity of the mud cake, and F: Formation resistivity factor 


\section{$4 \quad$ Results and Discussion}

\subsection{Estimate the total volume of the reservoir from the Isopach map:}

The figure (1) is an isopach map of V-NC6 area that we used to calculate the volume of the reservoir. Table 2 shows the results of reservoir volume calculations.

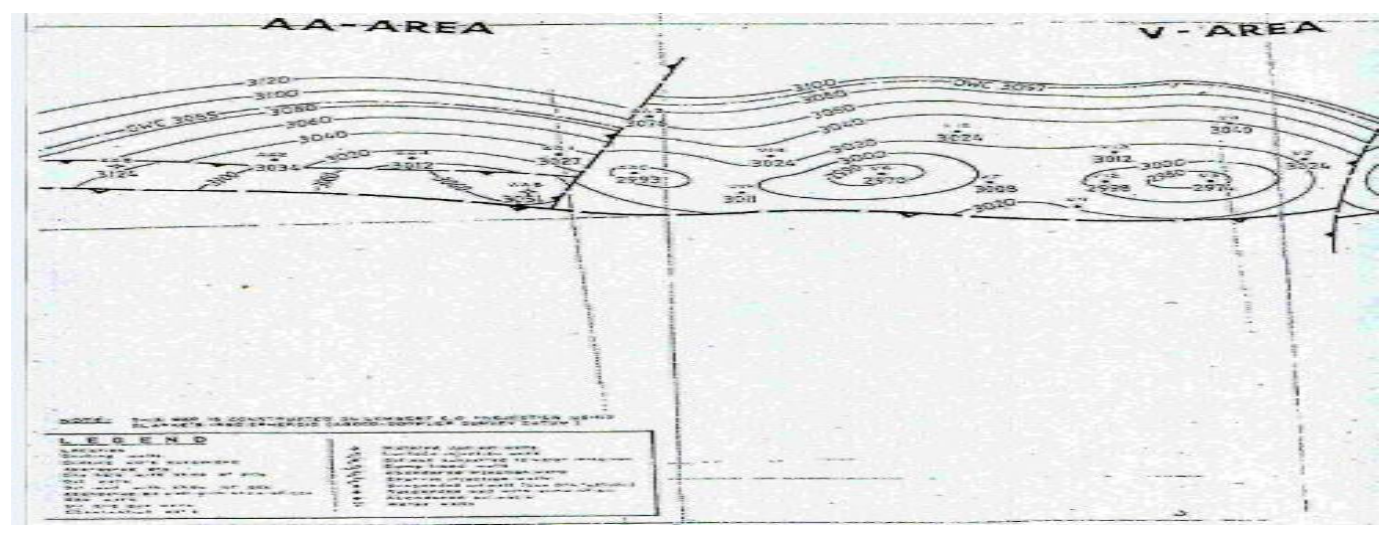

Figure (1) an isopach map of V-NC6 area of Alhamada Alhamra oil field.

Table 2 shows the results of reservoir volume calculations

\begin{tabular}{|c|c|c|c|c|c|}
\hline Area & $\mathrm{A}\left(\mathrm{Cm}^{2}\right)$ & $\mathrm{A}($ Acre $)$ & $\mathrm{A}_{\mathrm{n}} / \mathrm{A}_{\mathrm{n}-1}$ & Method Used & $\Delta \mathrm{VP}($ acre.ft $)$ \\
\hline $\mathrm{A}_{0}$ & 13.77 & 851.123 & - & - & - \\
\hline $\mathrm{A}_{1}$ & 9.31 & 575.137 & 0.6757 & Trapezoidal & 3565.65 \\
\hline $\mathrm{A}_{2}$ & 5.76 & 355.831 & 0.6186 & Trapezoidal & 2327.42 \\
\hline $\mathrm{A}_{3}$ & 3.11 & 192.124 & 0.5399 & Trapezoidal & 1369.88 \\
\hline $\mathrm{A}_{4}$ & 1.7 & 105.019 & 0.5466 & Trapezoidal & 742.85 \\
\hline $\mathrm{A}_{5}$ & 0.975 & 60.232 & 0.5735 & Trapezoidal & 330.502 \\
\hline
\end{tabular}

Total net pore volume $(\Delta \mathrm{VP})=8336.302$ acre.ft

\subsection{Estimate the porosity of the reservoir from the well logging:}

As example to calculate the porosity from well logging we estimated it from well V8. The figures $2 \& 3$ show the well head logs and the SP \& Electrical logs

of the well V8- NC6, respectively. Table 3 shows the results of the net pay thickness and porosity for each horizon of well V8.

Table 3 show the results of the net pay thickness and porosity for each horizon of well V8.

\begin{tabular}{|c|c|c|c|}
\hline Formation & Depth $(\mathrm{ft})$ & Thickness $(\mathrm{ft})$ & Porosity $(\%)$ \\
\hline $\mathrm{D}_{0}$ & 2950 & 19 & 0.253 \\
\hline $\mathrm{D}_{1}$ & 2977 & 23 & 0.141 \\
\hline $\mathrm{D}_{2}$ & 3019 & 46 & 0.144 \\
\hline $\mathrm{D}_{3}$ & 3083 & 67 & 0.153 \\
\hline
\end{tabular}

Proceedings of First Conference for Engineering Sciences and Technology (CEST-2018), vol. 1 283 
Verification of the reserve of Al-Hamada oil field V-NC6 area by application of well logs

And by Arche's method Equation (2), we can estimate the average porosity of the well (V8) as following:

$$
\emptyset_{\text {avg }}=\frac{\sum h * \emptyset}{\sum h} \quad \emptyset_{v 8}=\frac{(4.807+3.243+6.624+10.251)}{(19+23+46+67)}=16.08 \%
$$
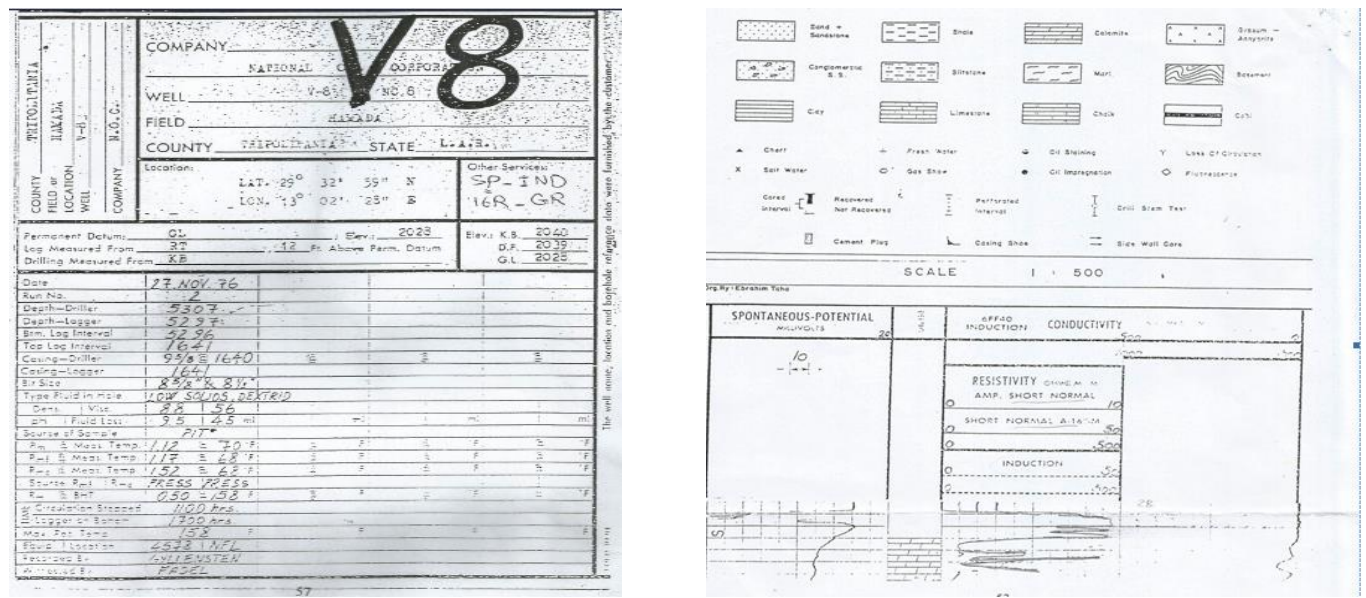

Figure 2 shows the well head logs of well V8
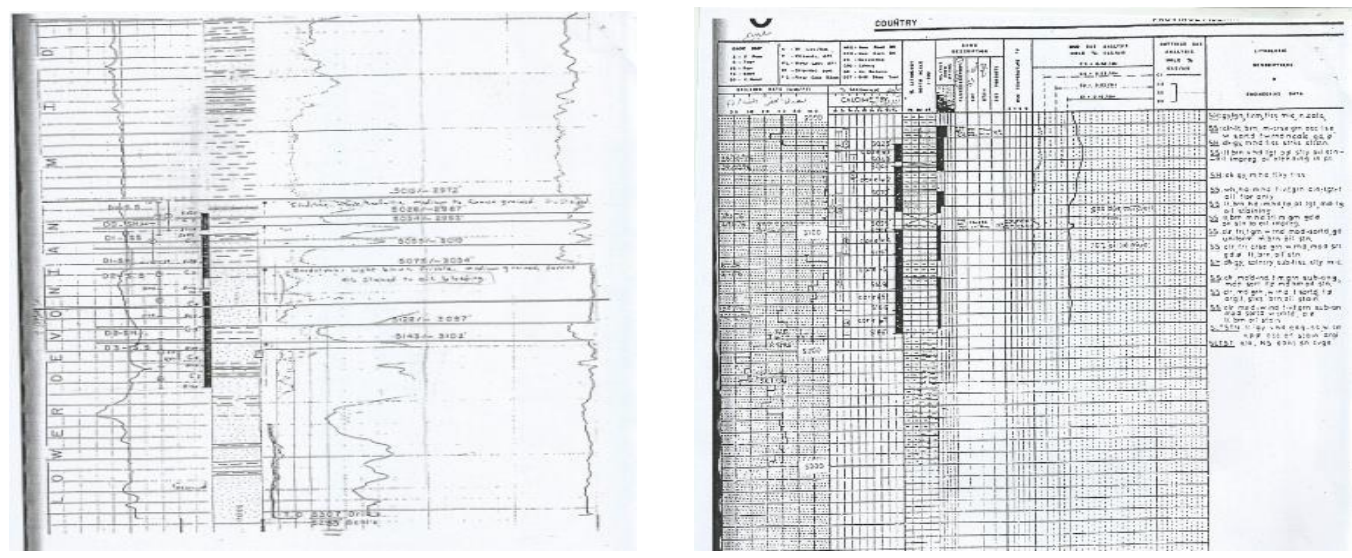

Figures 3 shows the SP \& Electrical logs of well V8

In addition, when we applied this equation for all the wells in the reservoir, we will estimate the average porosity of the reservoir. Table 4 shows the calculation and results of the average reservoir porosity of V-NC6 area. 
Basher et al., CEST-2018, AIJR Proceedings 2, pp.279-289, 2018

Table 4 shows the calculation and results of the average reservoir porosity of $V$-NC6 area.

\begin{tabular}{|c|c|c|c|c|}
\hline Well & Layer & H net (Ft.) & Ǿ \% & H* \\
\hline \multirow[t]{4}{*}{$\mathrm{V} 2$} & $\overline{D_{0}}$ & 11 & 0.132 & 1.452 \\
\hline & $\mathrm{D}_{1}$ & 10 & 0.125 & 1.25 \\
\hline & $\mathrm{D}_{2}$ & 16 & 0.147 & 2.352 \\
\hline & $\mathrm{D}_{3}$ & 26 & 0.131 & 3.406 \\
\hline \multirow[t]{4}{*}{ V4 } & $\mathrm{D}_{0}$ & 14 & 0.15 & 2.1 \\
\hline & $\mathrm{D}_{1}$ & 18 & 0.139 & 2.5 \\
\hline & $\mathrm{D}_{2}$ & 32 & 0.15 & 4.8 \\
\hline & $\mathrm{D}_{3}$ & 20 & 0.146 & 2.92 \\
\hline \multirow[t]{4}{*}{ V6 } & $\mathrm{D}_{0}$ & 0 & 0 & 0 \\
\hline & $\mathrm{D}_{1}$ & 29 & 0.13 & 3.8 \\
\hline & $\mathrm{D}_{2}$ & 16 & 0.123 & 1.9 \\
\hline & $\mathrm{D}_{3}$ & 32 & 0.14 & 4.55 \\
\hline \multirow[t]{4}{*}{ V7 } & $\mathrm{D}_{0}$ & 0 & 0 & 0 \\
\hline & $\mathrm{D}_{1}$ & 17 & 0.13 & 2.21 \\
\hline & $\mathrm{D}_{2}$ & 29 & 0.154 & 4.54 \\
\hline & $\mathrm{D}_{3}$ & 15 & 0.164 & 2.46 \\
\hline \multirow[t]{4}{*}{ V9 } & $\mathrm{D}_{0}$ & 10 & 0.253 & 2.53 \\
\hline & $\mathrm{D}_{1}$ & 9 & 0.141 & 1.26 \\
\hline & $\mathrm{D}_{2}$ & 51 & 0.144 & 7.344 \\
\hline & $\mathrm{D}_{3}$ & 13 & 0.153 & 1.989 \\
\hline \multirow[t]{4}{*}{ V13 } & $\mathrm{D}_{0}$ & 0 & 0 & 0 \\
\hline & $\mathrm{D}_{1}$ & 16 & 0.088 & 1.45 \\
\hline & $\mathrm{D}_{2}$ & 18 & 0.142 & 2.55 \\
\hline & $\mathrm{D}_{3}$ & 0 & 0 & 0 \\
\hline \multirow[t]{4}{*}{ V14 } & $\mathrm{D}_{0}$ & 3 & 0.144 & 0.432 \\
\hline & $\mathrm{D}_{1}$ & 9 & 0.135 & 1.215 \\
\hline & $\mathrm{D}_{2}$ & 29 & 0.133 & 3.79 \\
\hline & $\mathrm{D}_{3}$ & 22 & 0.137 & 3.014 \\
\hline \multirow[t]{4}{*}{ V15 } & $\mathrm{D}_{0}$ & 0 & 0 & 0 \\
\hline & $\mathrm{D}_{1}$ & 30 & 0.148 & 4.514 \\
\hline & $\mathrm{D}_{2}$ & 0 & 0 & 0 \\
\hline & $\mathrm{D}_{3}$ & 0 & 0 & 0 \\
\hline \multirow[t]{4}{*}{ V18 } & $\mathrm{D}_{0}$ & 12 & 0.152 & 1.748 \\
\hline & $\mathrm{D}_{1}$ & 21 & 0.095 & 1.995 \\
\hline & $\mathrm{D}_{2}$ & 0 & 0 & 0 \\
\hline & $D_{3}$ & 0 & 0 & 0 \\
\hline$\sum$ & & 630 & & 89.729 \\
\hline
\end{tabular}

$\sum \mathrm{H}^{*} \varnothing \dot{\varnothing}=89.729$

$\sum \mathrm{H}=630.5$

$$
\emptyset_{\text {avg }}=\frac{89.729}{630.5}=0.1423 \approx 14.23 \%
$$

The average reservoir porosity is 0.1423

Proceedings of First Conference for Engineering Sciences and Technology (CEST-2018), vol. 1 285 
Verification of the reserve of Al-Hamada oil field V-NC6 area by application of well logs

\subsection{Estimate the water saturation $(\mathrm{Sw})$ from the well logging:}

As example to estimate ( $\mathrm{Sw}$ ) from well logging we will estimate it from well V8:

Firstly we must find the value of (Rt) and (Rw)

-Rt from reading of the $\log =17.5 \mathrm{ohms} \mathrm{mm}$

- Estimate of Rt

\section{i- Rw with chart method at:}

$\mathrm{TD}=3250 \mathrm{ft}, \mathrm{BHT}=158$ F, Tavg $=68$ F \& Rmf =1.17 Ohm mm @ 68. The geothermal gradient $=2.769 \mathrm{~F}$ degree $/ 100$ feet

The chart (4) has been used to estimate the formation temperature, Tf. From chart (4) $\mathrm{Tf}=130 \mathrm{~F}$

The chart (5) has been used to estimate the mud and mud filtrate resistivities.

From chart (5)Rmf@130 F = 0.6 Ohm mm

The chart (6) has been used to estimate the equivalent mud filtrate resistivity

From chart (6) Rmfeq $=0.375 \mathrm{Ohm} \mathrm{mm}$

The chart (7) has been used to estimate the equivalent water resistivity.

From chart (7) and at $\mathrm{SP}=-70$ milvolts (from log)

Rweq $=0.046 \mathrm{Ohm} \mathrm{mm}$

From chart (6) Rw $=0.062 \mathrm{Ohm} \mathrm{mm}$

ii- Rw with ARP'S equation at :

Tavg $=68 \mathrm{~F}, \mathrm{BHT}=158 \mathrm{~F}, \mathrm{Df}=2950 \mathrm{ft} \& \mathrm{Dt}=3250 \mathrm{ft}$

$\mathrm{R} 1-1.17 @ 68 \mathrm{~F}$ and $\mathrm{SP}=-70$ milvolts (from $\log$ ) and $\mathrm{T} 2=149.7^{\circ} \mathrm{F}$

R2 (New Rmf); R2=0.5591 Ohm mm, thus (New Rmf) R2 $>0.1$ 
Basher et al., CEST-2018, AIJR Proceedings 2, pp.279-289, 2018

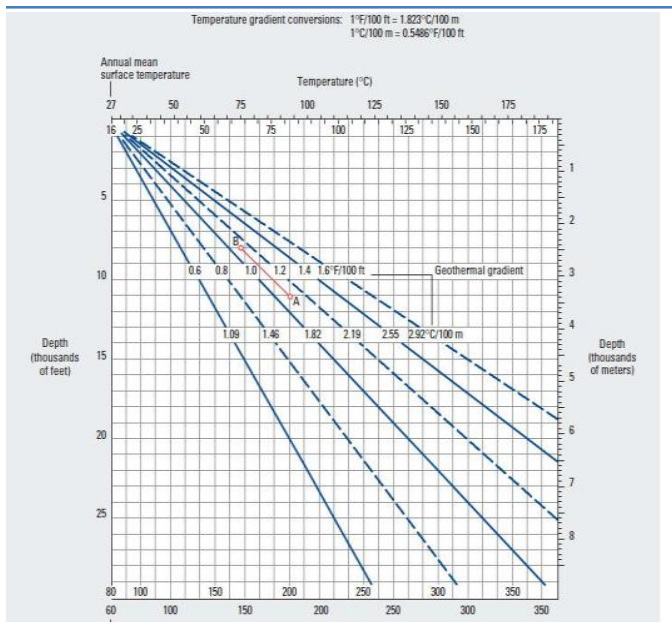

The chart (4) estimation of formation temperature, Tf.

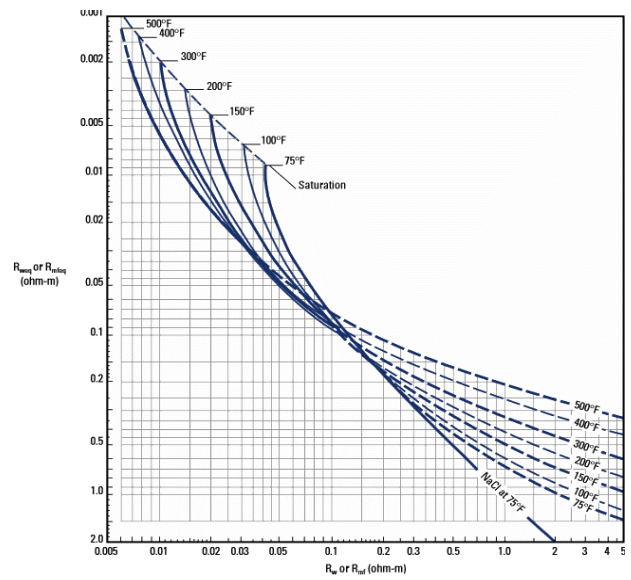

The chart (6) to estimate the $R m \& R w$.

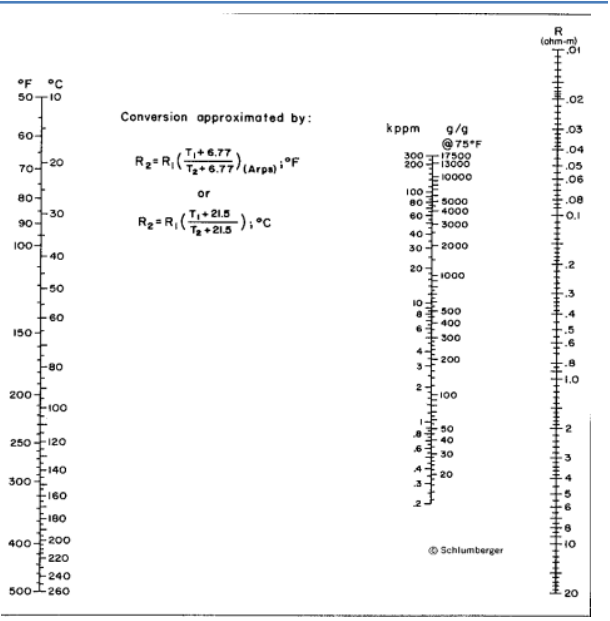

The chart (5) to estimate the Rmf \& Rweq.

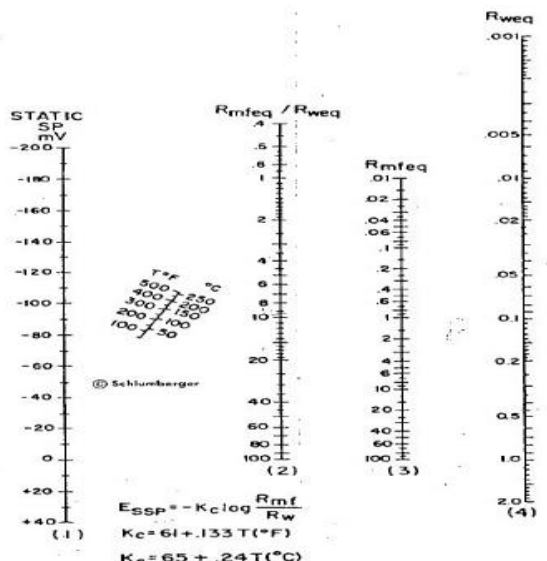

The chart (7) to estimate the Rmfeq.

iii- Rmfeq $=0.4752 \mathrm{Ohm} \mathrm{mm}$

iv- Constant $(K)=79.91$

$\mathrm{Rw}=-0.58+0.7158=0.131 \mathrm{Ohm} \mathrm{mm}$

Convert the Rw to Rw@Tf; Rw=0.0626 Ohm mm

vii- To find $\mathrm{Ro}=\mathrm{F} * \mathrm{Rw}$

For sand stone formation and $\emptyset$ is average porosity of well V8

$\mathrm{F}=31.54$, thus $\mathrm{Ro}=1.97447 \mathrm{Ohm} \mathrm{mm}$

Sw v8 $=0.33532=33.5 \%$

Proceedings of First Conference for Engineering Sciences and Technology (CEST-2018), vol. 1 287 
Verification of the reserve of Al-Hamada oil field V-NC6 area by application of well logs

And by applied the Arch,s equation for all the wells in the reservoir, we will estimate the average water saturation of it. Table 5 shows the application of Arch's equation for all wells on V-NC6 area.

Table 5 shows the application of Arch's equation for all wells on V-NC6 area.

\begin{tabular}{|c|c|c|c|c|c|}
\hline Well & Layer & H net (Ft.) & $\varnothing \dot{\varnothing} \%$ & Sw \% & $\mathrm{H}^{*} \varnothing{ }^{*} \mathrm{Sw}$ \\
\hline \multirow[t]{4}{*}{ V2 } & $\overline{\mathrm{D}_{0}}$ & 11 & 0.132 & 0.201 & 0.2918 \\
\hline & $\mathrm{D}_{1}$ & 10 & 0.125 & 0.208 & 0.26 \\
\hline & $\mathrm{D}_{2}$ & 16 & 0.147 & 0.279 & 0.656 \\
\hline & $\mathrm{D}_{3}$ & 26 & 0.131 & 0.303 & 1.032 \\
\hline \multirow[t]{4}{*}{ V4 } & $\mathrm{D}_{0}$ & 14 & 0.15 & 0.19 & 0.399 \\
\hline & $\mathrm{D}_{1}$ & 18 & 0.139 & 0.228 & 0.57 \\
\hline & $\mathrm{D}_{2}$ & 32 & 0.15 & 0.193 & 0.94 \\
\hline & $\mathrm{D}_{3}$ & 20 & 0.146 & 0.36 & 1.051 \\
\hline \multirow[t]{4}{*}{ V6 } & $\mathrm{D}_{0}$ & 0 & 0 & 0 & 0 \\
\hline & $\mathrm{D}_{1}$ & 29 & 0.13 & 0.494 & 1.894 \\
\hline & $\mathrm{D}_{2}$ & 16 & 0.123 & 0.596 & 1.172 \\
\hline & $\mathrm{D}_{3}$ & 32 & 0.14 & 0.429 & 1.951 \\
\hline \multirow[t]{4}{*}{ V7 } & $\mathrm{D}_{0}$ & 0 & 0 & 0 & 0 \\
\hline & $\mathrm{D}_{1}$ & 17 & 0.13 & 0.251 & 0.544 \\
\hline & $\mathrm{D}_{2}$ & 29 & 0.154 & 0.372 & 0.168 \\
\hline & $\mathrm{D}_{3}$ & 15 & 0.164 & 0.377 & 0.927 \\
\hline \multirow[t]{4}{*}{ V9 } & $\overline{D_{0}}$ & 10 & 0.253 & 0.399 & 1.009 \\
\hline & $\mathrm{D}_{1}$ & 9 & 0.141 & 0.474 & 0.601 \\
\hline & $\mathrm{D}_{2}$ & 51 & 0.144 & 0.303 & 2.225 \\
\hline & $\mathrm{D}_{3}$ & 13 & 0.153 & 0.299 & 0.594 \\
\hline \multirow[t]{4}{*}{ V13 } & $\mathrm{D}_{0}$ & 0 & 0 & 0 & 0 \\
\hline & $\mathrm{D}_{1}$ & 16 & 0.088 & 0.371 & 0.538 \\
\hline & $\mathrm{D}_{2}$ & 18 & 0.142 & 0.278 & 0.710 \\
\hline & $\mathrm{D}_{3}$ & 0 & 0 & 0 & 0 \\
\hline \multirow[t]{4}{*}{ V14 } & $\mathrm{D}_{0}$ & 3 & 0.144 & 0.614 & 0.2652 \\
\hline & $\mathrm{D}_{1}$ & 9 & 0.135 & 0.188 & 0.22842 \\
\hline & $\mathrm{D}_{2}$ & 29 & 0.133 & 0.274 & 1.038 \\
\hline & $\mathrm{D}_{3}$ & 22 & 0.137 & 0.381 & 1.1483 \\
\hline \multirow[t]{4}{*}{ V15 } & $\overline{D_{0}}$ & 0 & 0 & 0 & 0 \\
\hline & $\mathrm{D}_{1}$ & 30 & 0.148 & 0.238 & 1.0743 \\
\hline & $\mathrm{D}_{2}$ & 0 & 0 & 0 & 0 \\
\hline & $\mathrm{D}_{3}$ & 0 & 0 & 0 & 0 \\
\hline \multirow[t]{4}{*}{ V18 } & $\mathrm{D}_{0}$ & 12 & 0.152 & 0.409 & 0.7149 \\
\hline & $\mathrm{D}_{1}$ & 21 & 0.095 & 1.097 & 1.09725 \\
\hline & $\mathrm{D}_{2}$ & 0 & 0 & 0 & 0 \\
\hline & $\mathrm{D}_{3}$ & 0 & 0 & 0 & 0 \\
\hline$\sum$ & & 630 & & & 26.93079 \\
\hline
\end{tabular}

$\sum \mathrm{H}^{*} \varnothing \dot{\varnothing}=89.729 \& \sum \mathrm{H}^{*} \varnothing \varnothing^{*} \mathrm{Sw}=26.93079$ 
$S W_{\text {avg }}=\frac{26.93097}{89.729}=0.30013 \approx 30 \%$

\subsection{Estimate the Original Oil in Place (OOIP) with Volumetric Equation:}

$\Delta \mathrm{BV}=8336.3$ acre ft., porosity of the reservoir $=0.142314$, average water saturation of the reservoir $=0.300137$ and the oil formation volume factor $($ Boi $)=1.165$

OOIP $=5.43924 * 10^{6}$ STB

\section{Conclusions and Recommendations}

From drilling, testing and logging results, it is concluded that V8-NC6 well proved to be one of the best oil wells in Elhamada Alhamra oil field in the "V" structure. The gross thickness of the pay zone attains 154` while the net oil sands attains about 105`. On top of the pay zone "Lower Devonian Sandstone". The D 0 Sandstone was net at 2971 ` leveled with V6-NC6 well. The $\mathrm{D}_{2}$ Sandstone was proved the thickness in the area since it attains $53^{\prime}$ in the well V8 while its thickness is $40^{\circ}$ in V6. It was decided to start production from $\mathrm{D}_{3}$ sandstone at first through the perforated interval $5151^{`}-5159^{`}$ and left the other zones for future planning. It was recommended to drill a development well between the eastern and western culmination of the "V" structure I.e. between V7 and V8-NC6 wells to check the oil water contact in the $\mathrm{D}_{2}$ sandstone unit.

\section{Acknowledgment}

We do thank the Arabian Gulf Oil Company for their help and support in providing the required data for this paper, as well as our staff member of Sirte University.

\section{References}

[1] Pletcher, J.L., 2002. Improvements to Reservoir Material-Balance Methods. SPE, pp. 49-59

[2] Konak, A., David, Coit, W., Alice, Smith, E., 2006. Multi-objective optimization using genetic algorithms: a tutorial. Reliab Eng Syst Saf 91 (No. 9), 992-1007.

[3] Schulze, R.W., Riegret, Axmann, J.K., Hease, O., Rian, D.T., You, Y.L., 2002. Evaluationary algorithms applied to history matching of complex reservoirs. SPE Reser Evalu Eng 5 (2), 163-175.

[4] Donald P. Helander - Fundamentals of Formation Evaluation. Copyrights @ 1983 Tulsa, Oklahoma. Alfred Mayer. Gurr-Petroleum Engineering @ Ferdinand Enke publishers Stuttgart 1976.

[5] Craft and Hawkins- Applied Petroleum Reservoir Engineering, Louisiana State University 1959.

[6] MJ. Salem \& Hammuda - Gelogy of Libya Volumes I \& II, copyright (C 1991 by Tripoli University, Tripoli. 